\title{
DYNAMICAL BEHAVIOR OF RAPESEED OIL AND METHYL ESTER OF RAPESEED OIL DURING HIGH-PRESSURE INJECTION
}

\section{Dumitru BAMBULEAC $•$}

\begin{abstract}
Fuels' physical properties such as density, viscosity, speed of sound and bulk modulus have and important influence on the engine performance. This work will study the behavior of the rapeseed oil and methyl ester of rapeseed oil during high-pressure injection. Several aspects of the injection and combustion process will be analyzed in order to try to find out in what manner these aspects are influenced by the above-mentioned fuels' characteristics and also by different operating regimes. In such a way, some features of the technical efficiency of the two non-conventional diesel fuels will be determined. As a reference, it will serve the results from testing classical diesel.
\end{abstract}

\section{INTRODUCTION}

\subsection{THE PURPOSE OF THE STUDY}

On a global level, rapeseed oil based biodiesel fuels, as well as possibility to use straight vegetable oil as diesel fuel, have been intensively investigated. The motivation to research and develop alternative fuels is determined by some factors, such as: the growing demand for energy, depletion of fossil petroleum reserves, increasing price of the traditional fuels, political concerns and environmental issues. Bio-fuels, particularly rapeseed oil and rapeseed oil methyl ester, might help a lot to meet the future energy supply demands as well as contributing to the reduction of greenhouse gases emissions and other harmful products of the combustion process.

But, there isn't now a general scientific consensus on the idea that crop-based fuels could serve as a real alternative to the use of conventional diesel in transportation. People who have a skeptical approach to this perspective support the argument that the agricultural fields must be used to grow plants necessary to satisfy the increasing need in food on the global level. Also, some scientists may affirm that, in case the alternative bio-fuels would become subjects of the fuel taxes, their price will significantly increase and their production will not be economically efficient.

On the other hand, the era of cheap and secure fuel (cheap energy) is over [1]. That's why several energy alternatives to power the vehicles are being explored. Since fuel cells-based, electric/hybrid transport units are still a long way from becoming mainstream ones, the use of the bio-fuels is extremely actual. The main reasons for the promotion of bio-fuels can be summarized as:

- Bio-fuels can improve independence and energy security;

- Bio-fuels may contribute to a reduction in carbon emissions;

- Bio-fuels can help to increase farm income and contribute to rural development.

• Dumitru Bambuleac, Republic of Moldova, dima.bambuleac@gmail.com 
During a series of laboratory experiments, two different alternative bio-fuels for compression ignition (CI) engines were studied - straight rapeseed oil (RO) and methyl ester of rapeseed oil (FAME), as well as diesel fuel, used as an reference. The reason was to determinate their technical capacity to become successful substitutes of the regular diesel. Several parameters and outputs of the engine operation were collected, analyzed and compared to those obtained during usage of classic fuel. All the fuels were tested in exactly same conditions and regimes.

A previous paper [3] presents the examination of the exhaust emissions and indicated incylinder pressure. This paper presents the results of the analysis of the fuel pressure inside the fuel-line and some relevant injection and combustion parameters. The main goal is to research how fuels' chemical and physical properties influence the combustion process.

\subsection{RAPESEED OIL AS AN ALTERNATIVE FUEL FOR CI ENGINES}

Rapeseed oil is of vegetable origin and is obtained from crushed rapeseeds by pressing or extraction. Among different kinds of vegetable oils, rapeseed is the best one for use as a fuel, as it is relatively thin, cheap to produce and easy to get hold of. Rapeseed oil can be used as diesel fuel just as it is, without being converted to biodiesel. The downside is that straight vegetable oil is much more viscous (thicker) than conventional diesel fuel or biodiesel (Table 1) and it doesn't burn in the same way in the engine. This problem can be solved by using a two-tank system which pre-heats the rapeseed oil to make it thinner [2]. The vehicle is started up on a thin, highly combustible fuel such as fossil diesel and then switched over to the vegetable oil from second tank and switched back again to the petro-diesel tank before stopping the engine.

\subsection{RAPESEED OIL METHYL ESTER AS AN ALTERNATIVE FUEL FOR CI ENGINES}

Rapeseed oil methyl ester is a biodiesel made from rapeseed oil (consisting mainly of triglycerides) reacted with methanol in presence of a catalyst. This chemical reaction is known as transesterification (Fig.1).

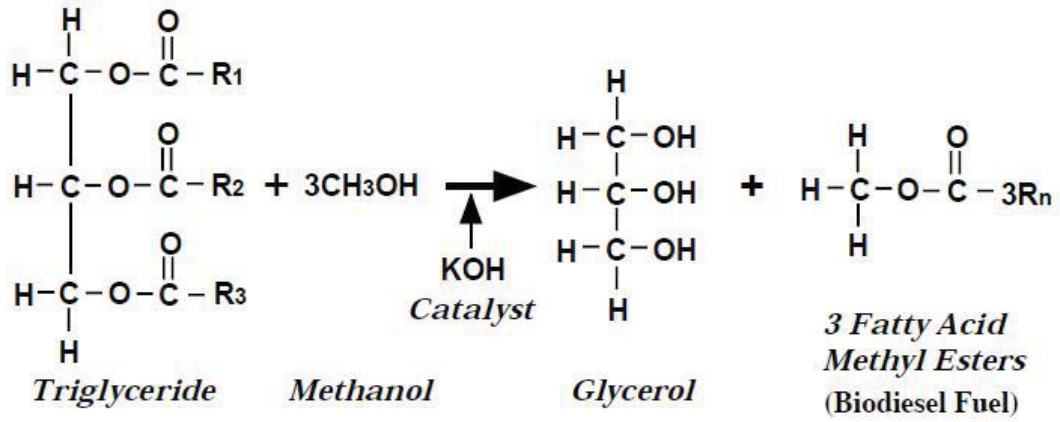

Figure 1: The transesterification reaction. $R_{1,2,3, n}$ are various fatty acid chains

The obtained biodiesel - rapeseed oil methyl ester - has much lower viscosity than straight rapeseed oil (Table 1 ) and can be used as a fuel for compression ignition engines without operational problems, such as engine deposits, and without the need to install or to adjust special equipment in the fuel system.

\section{EXPERIMENTAL}

The experimental work was carried on a Zetor 1505 (Zetor, Brno, Czech Republic) fourcylinder direct-injection turbocharged diesel tractor engine with a bore of $105 \mathrm{~mm}$, stroke of $120 \mathrm{~mm}$, a displacement of 4.156 liters, a rated power of $90 \mathrm{~kW}$ (120 hp) at $2200 \mathrm{rpm}$ and a rated maximum torque of $450 \mathrm{Nm}$ at $1480 \mathrm{rpm}$; this corresponds to a brake mean effective pressure (BMEP) of $1588 \mathrm{kPa}$. 
This engine utilizes a fully mechanically controlled Motorpal (Motorpal, Jihlava, Czech Republic) gear-driven inline fuel injection pump with constant static injection timing. The static injection timing was 10 degrees BTDC. The pump is lubricated by engine oil. The timing of the beginning of the injection is constant for all rpm and loads and was verified to be at manufacturer's specification. The specified injector opening pressure is 25 MPa.The engine was also equipped with stock alternator, air compressor, and a twospeed radiator/intercooler cooling fan. The tested engine used an exhaust gas recirculation (EGR) system, which was observed to be active at both 1480 and $2200 \mathrm{rpm}$ and below approximately $80 \%$ of the rated power and inactive along the maximum torque curve and at idle.

The engine was coupled to a Schenck Dynabar D-630 water brake dynamometer.

The engine was operated alternately on highway diesel fuel (EN 590, from ETK, Liberec, Czech Republic), on locally produced fuel-grade (DIN 51605) rapeseed oil - RO (FabioProduct, Holin, Czech Republic) and methylester of rapeseed oil - FAME (Agropodnik, Jihlava, Czech Republic). The rapeseed oil composition by weight was $76.1 \%$ carbon, $15.4 \%$ hydrogen and $8.5 \%$ oxygen.

Some of the selected fuels' properties are shown in the table 1.

The engine was equipped with an auxiliary fuel-system, heated by the engine cooling water, allowing the start of the engine on diesel fuel and operation of the engine on either diesel fuel or heated rapeseed oil [3]. The fuel temperature was maintained around $70^{\circ} \mathrm{C}$.

Table 1: Selected properties of the used fuels [4]

\begin{tabular}{|c|c|c|c|}
\hline Fuel & Diesel fuel & Rapeseed oil & Biodiesel \\
\hline Standard & EN 590 & DIN 51605 & EN 14214 \\
\hline Density for $15^{\circ} \mathrm{C},\left[\mathrm{kg} / \mathrm{m}^{3}\right]$ & $820-845$ & $900-930$ & $860-900$ \\
\hline Viscosity for $40^{\circ} \mathrm{C},\left[\mathrm{mm}^{2} / \mathrm{s}\right]$ & $2.0-4.5$ & $<36$ & $3.5-5.5$ \\
\hline Flash point, $\left[{ }^{\circ} \mathrm{C}\right]$ & $>55$ & $>220$ & $>120$ \\
\hline Cetane number & $>51$ & $>39$ & $>51$ \\
\hline \multicolumn{2}{|c|}{ Non-regulated properties } \\
\hline Lower heating value, $[\mathrm{MJ} / \mathrm{kg}]$ & $42-43$ & $36-37$ & $\sim 37$ \\
\hline Oxygen content & Negligible & $10-11 \%$ & $10-11 \%$ \\
\hline Speed of sound, $[\mathrm{m} / \mathrm{s}]$ & 1380 & 1470 & 1410 \\
\hline
\end{tabular}

For each kind of tested fuel the engine was run following the working cycles:

-1- 3 times maximum torque curve (from 1000 to $2400 \mathrm{rpm}$ at full load)

-2- Modes 1, 2, 3 of ISO $8178 \mathrm{C}-1$ test (table 2)

-3- ISO 8178 C-1 test

-4- ISO 8178 C-2 test without mode 2 (full load at max. torque rpm) (table 3)

-5- Modes 4, 5 of ISO 8178 C-2 test

Normally, it have been run 6 minutes per mode, some modes in the C-2 test have longer run time to collect the needed amount of particulate matter for analysis. 
Table 2: Used ISO $8178 \mathrm{C}-1$ test cycles

\begin{tabular}{|c|c|c|c|c|c|c|c|c|}
\hline mode & 1 & 2 & 3 & 4 & 5 & 6 & 7 & 8 \\
\hline Speed, $[\mathrm{rpm}]$ & 2200 & 2200 & 2200 & 2200 & 1480 & 1480 & 1480 & 780 \\
\hline Torque, $[\mathrm{Nm}]$ & 330 & 247 & 165 & 33 & 450 & 337 & 225 & 0 \\
\hline
\end{tabular}

Table 3: Used ISO $8178 \mathrm{C}-2$ test cycles

\begin{tabular}{|c|c|c|c|c|c|c|}
\hline mode & 1 & 2 & 3 & 4 & 5 & 8 \\
\hline Speed, $[\mathrm{rpm}]$ & 2200 & 1480 & 1480 & 1480 & 1480 & 780 \\
\hline Torque, $[\mathrm{Nm}]$ & 88 & 337 & 225 & 112 & 45 & 0 \\
\hline
\end{tabular}

Indicated combustion pressures inside the cylinder were measured by an un-cooled piezoelectric indicated pressure transducer (GM11, AVL, Austria) fitted into an adapter inserted in place of a glow plug of the no. 1 cylinder and by an opto-mechanical sensor (PSI-Glow, Optrand, Troy, Michigan, USA) inserted in place of the glow plug of the no. 4 cylinder and a dynamic pressure sensor (Kistler, Winterthur, Switzerland) installed in the high-pressure injection line on no. 1 cylinder. The output of these sensors was synchronized with the incremental crankshaft position sensor and recorded at the increments of 0.1 degrees of crankshaft rotation (Indimeter 619, AVL, Graz, Austria).

\section{RESULTS}

The fuel density and viscosity have an important influence on the efficiency of the combustion process. Higher fuel density leads to a higher pressure inside the fuel line. Higher pressure produces better fuel atomization, phenomenon which has a positive impact on the combustion and, consequently, on the engine output. On the other hand, it is well known that higher fuel density and viscosity leads to a poorer quality atomization. So, there is contradiction. Difference in fuels' properties can have both positive and negative effects on combustion.

In this chapter, diagrams representing the fuel-line pressures and indicated pressures are given. Having the characteristics of the studied bio-fuels (Table 1), these diagrams will be analyzed in order to determinate the influence of the different fuel properties on the combustion process. As reference, the results of the testing of conventional diesel will be used.

For simplicity, seven representative regimes were selected:

- $2200 \mathrm{rpm}$ and $330 \mathrm{Nm}$ torque (100\% engine load) (Fig. 2a);

- $2200 \mathrm{rpm}$ and $247 \mathrm{Nm}$ (75\% engine load) (Fig. 2b);

- $2200 \mathrm{rpm}$ and $33 \mathrm{Nm}$ (10\% engine load) (Fig. 2c);

- $1480 \mathrm{rpm}$ and $337 \mathrm{Nm}$ (75\% engine load) (Fig. 2d);

- $1480 \mathrm{rpm}$ and $337 \mathrm{Nm}$ (75\% engine load) (Fig. 2e);

- $1480 \mathrm{rpm}$ and $45 \mathrm{Nm}$ (10\% engine load) (Fig. 2f);

- 780 rpm and no load (idling regime) (Fig. $2 \mathrm{~g}$ ). 


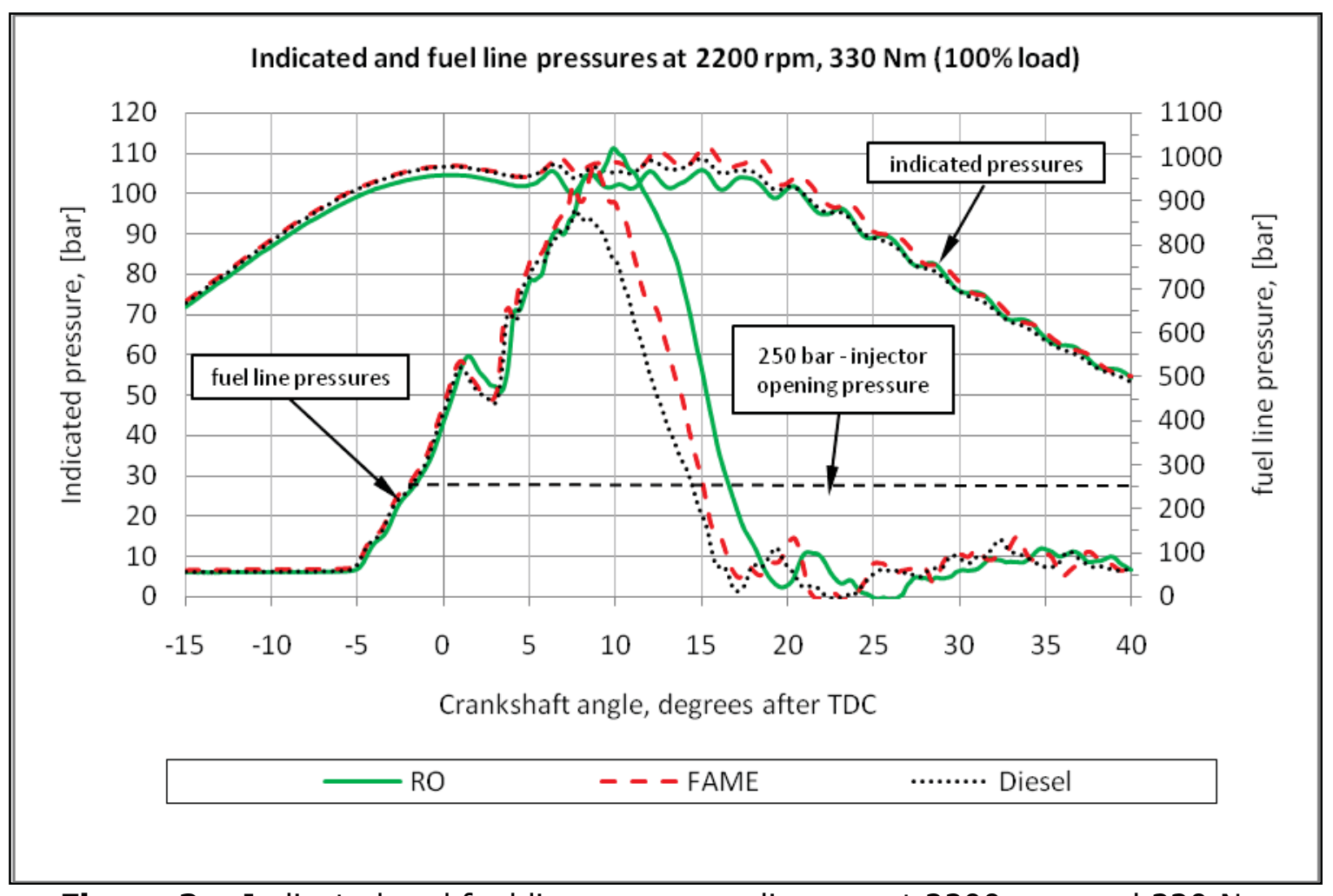

Figure 2a: Indicated and fuel line pressures diagram at $2200 \mathrm{rpm}$ and $330 \mathrm{Nm}$

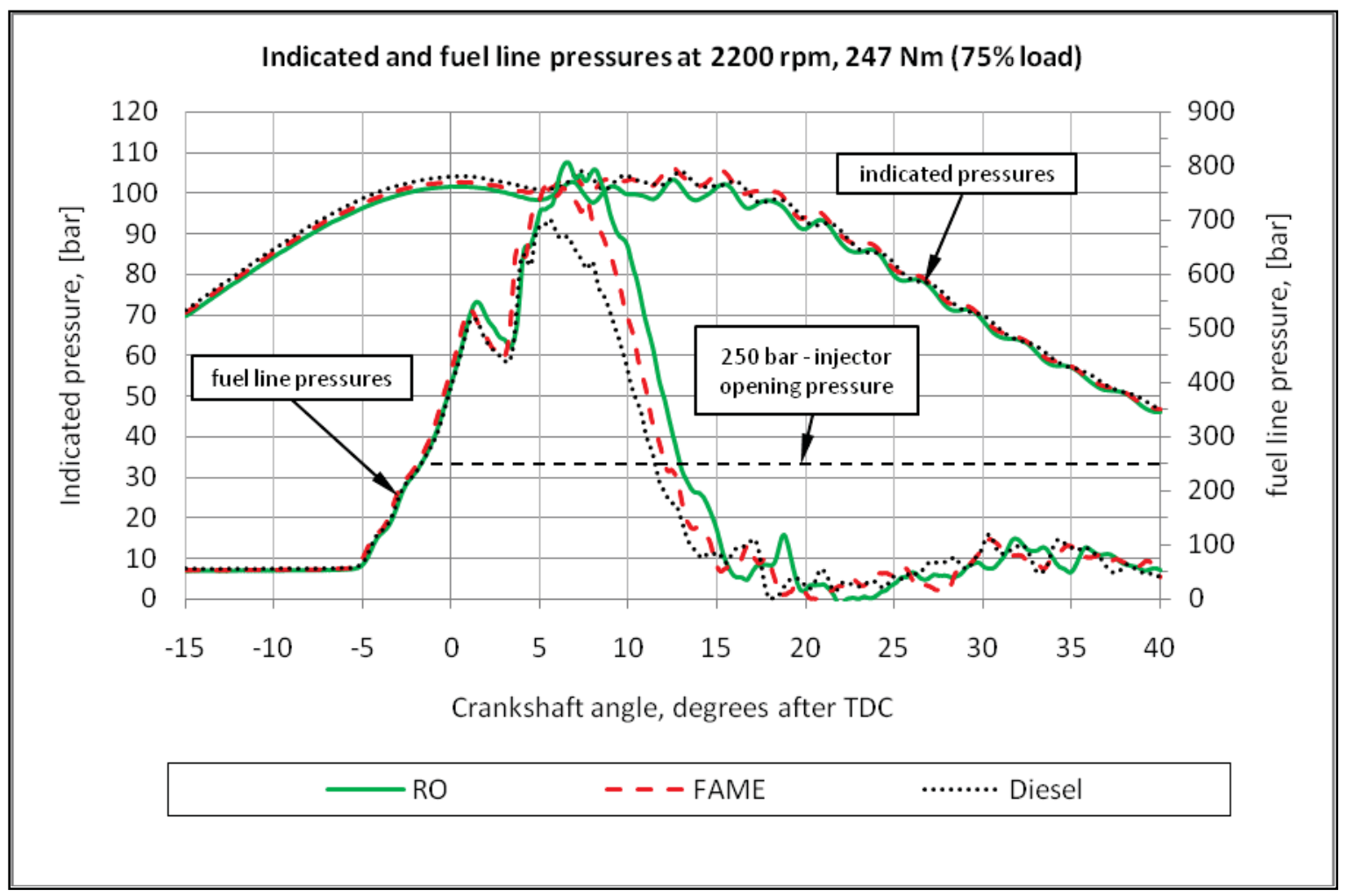

Figure 2b: Indicated and fuel line pressures diagram at $2200 \mathrm{rpm}$ and $247 \mathrm{Nm}$ 
Indicated and fuel line pressures at $2200 \mathrm{rpm}, 33 \mathrm{Nm}$ (10\% load)

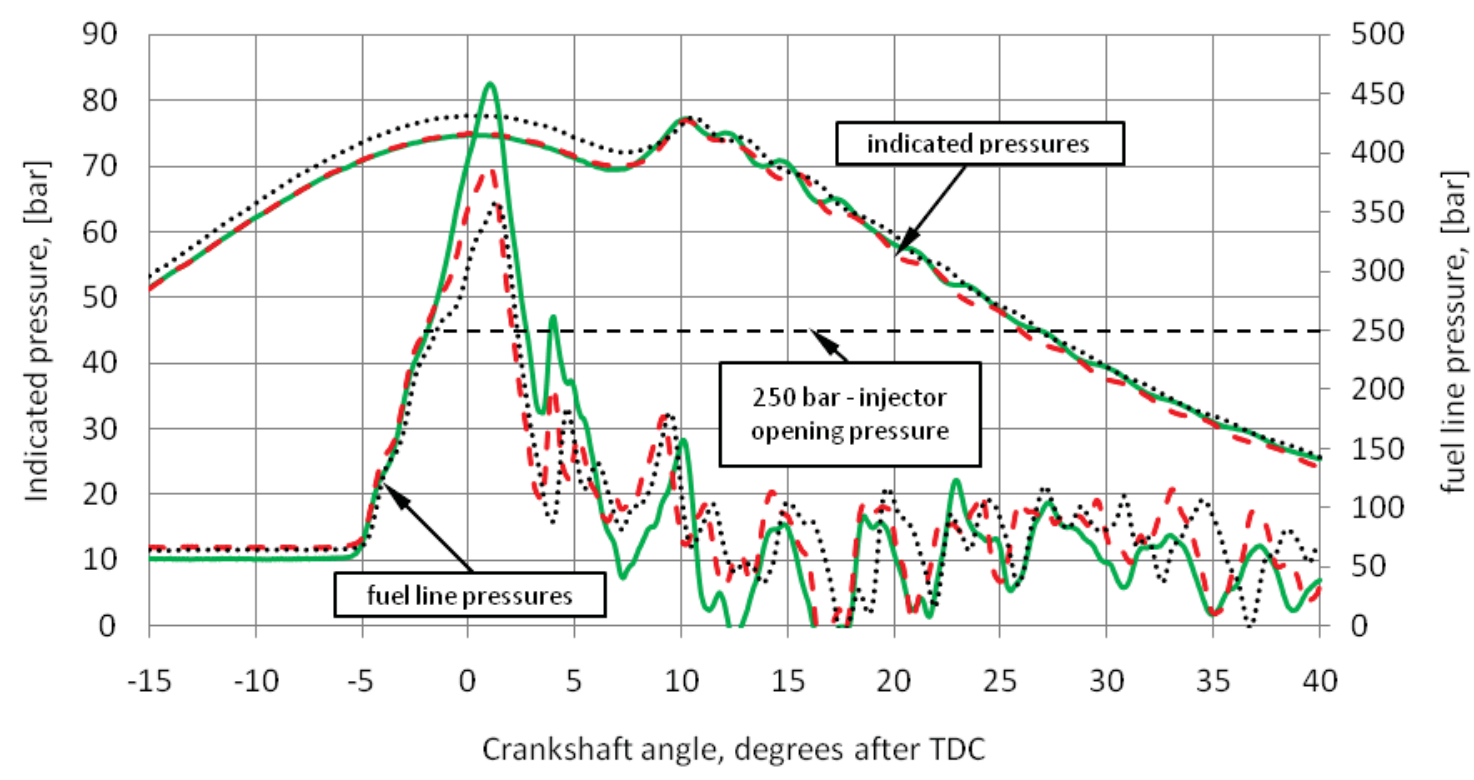

\begin{tabular}{lll|}
\hline RO & --- FAME & $\cdots \cdots$ \\
\hline
\end{tabular}

Figure 2c: Indicated and fuel line pressures diagram at $2200 \mathrm{rpm}$ and $33 \mathrm{Nm}$

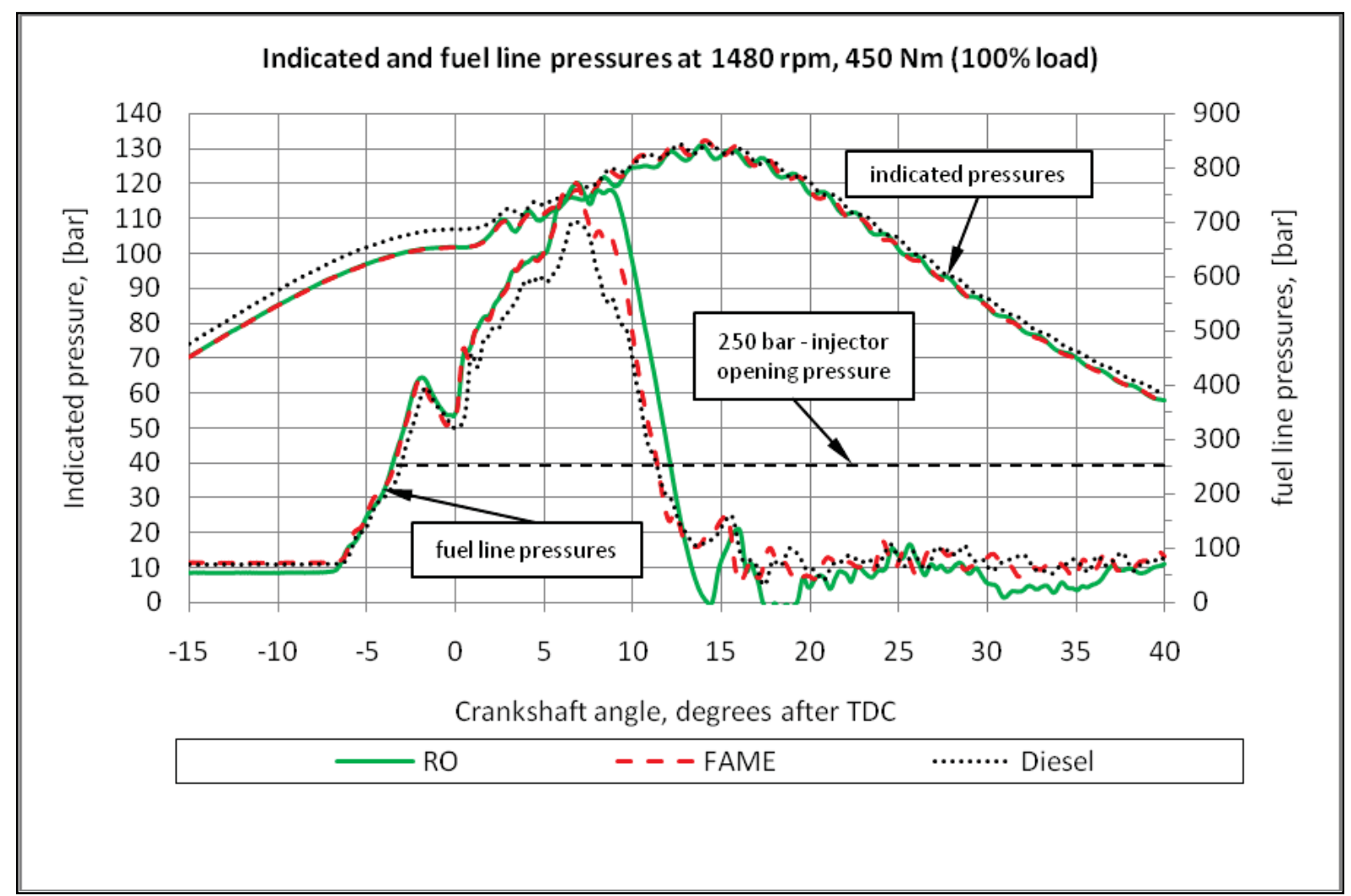

Figure 2d: Indicated and fuel line pressures diagram at $1480 \mathrm{rpm}$ and $450 \mathrm{Nm}$ 


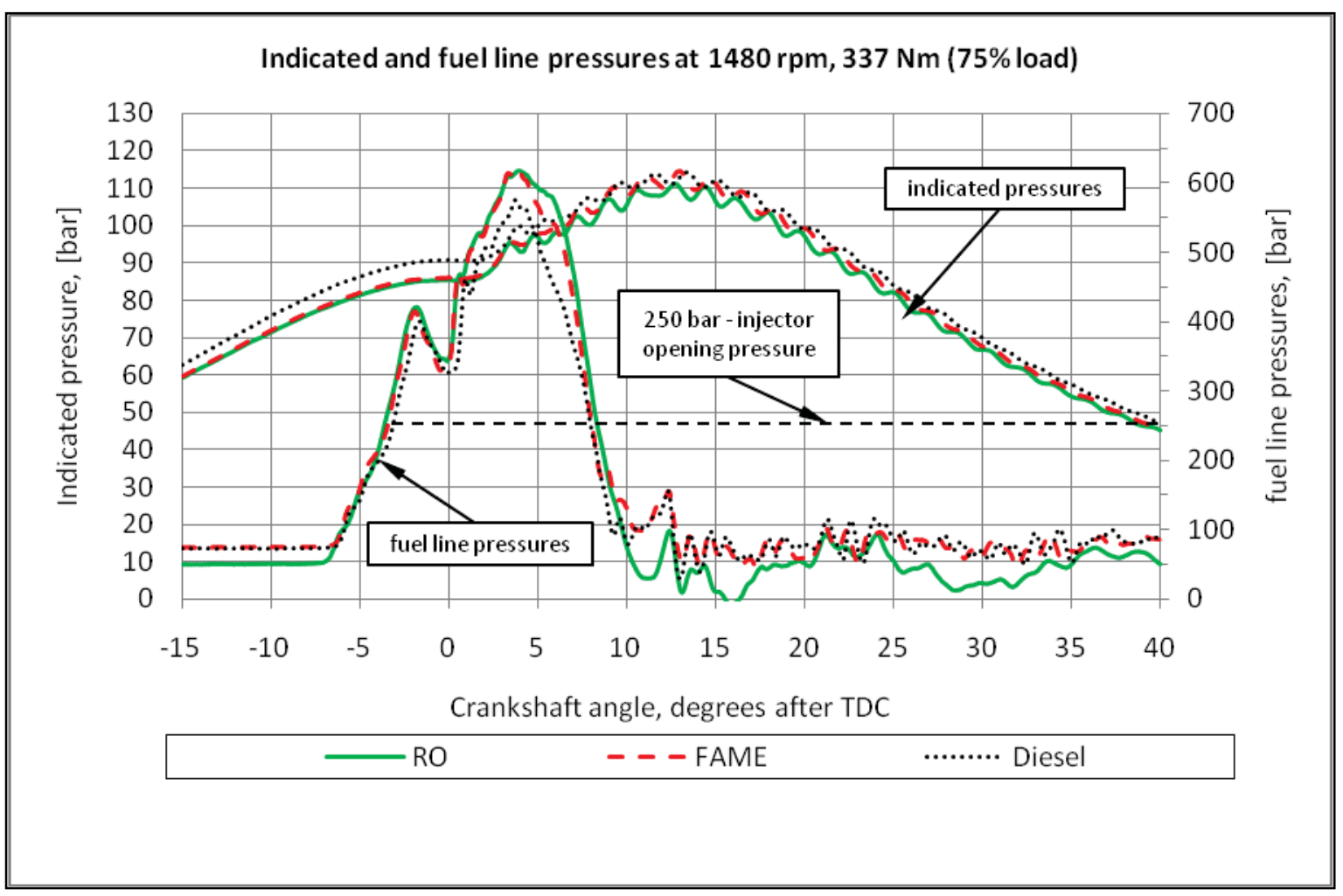

Figure 2e: Indicated and fuel line pressures diagram at $1480 \mathrm{rpm}$ and $337 \mathrm{Nm}$

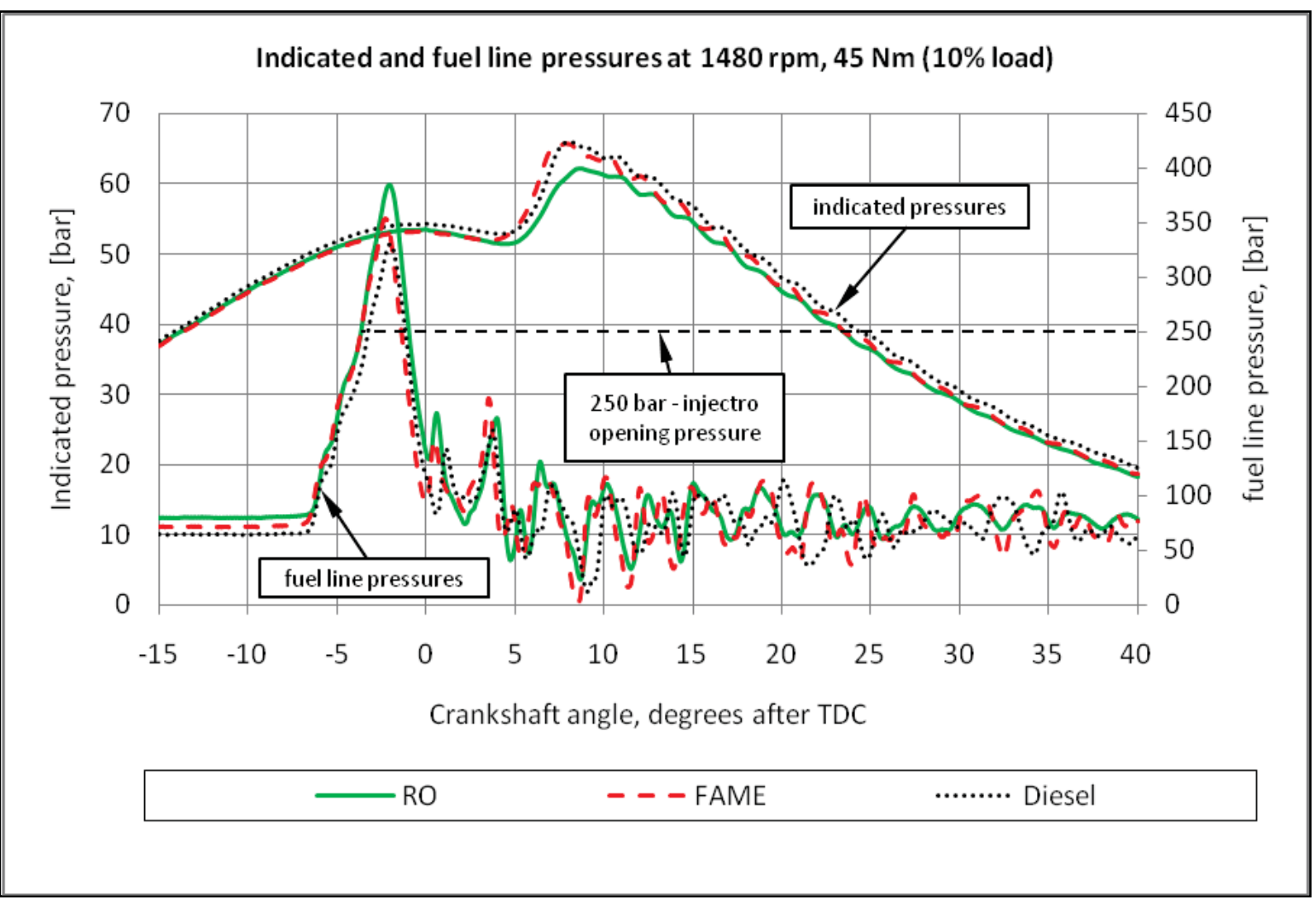

Figure 2f: Indicated and fuel line pressures diagram at $1480 \mathrm{rpm}$ and $45 \mathrm{Nm}$ 


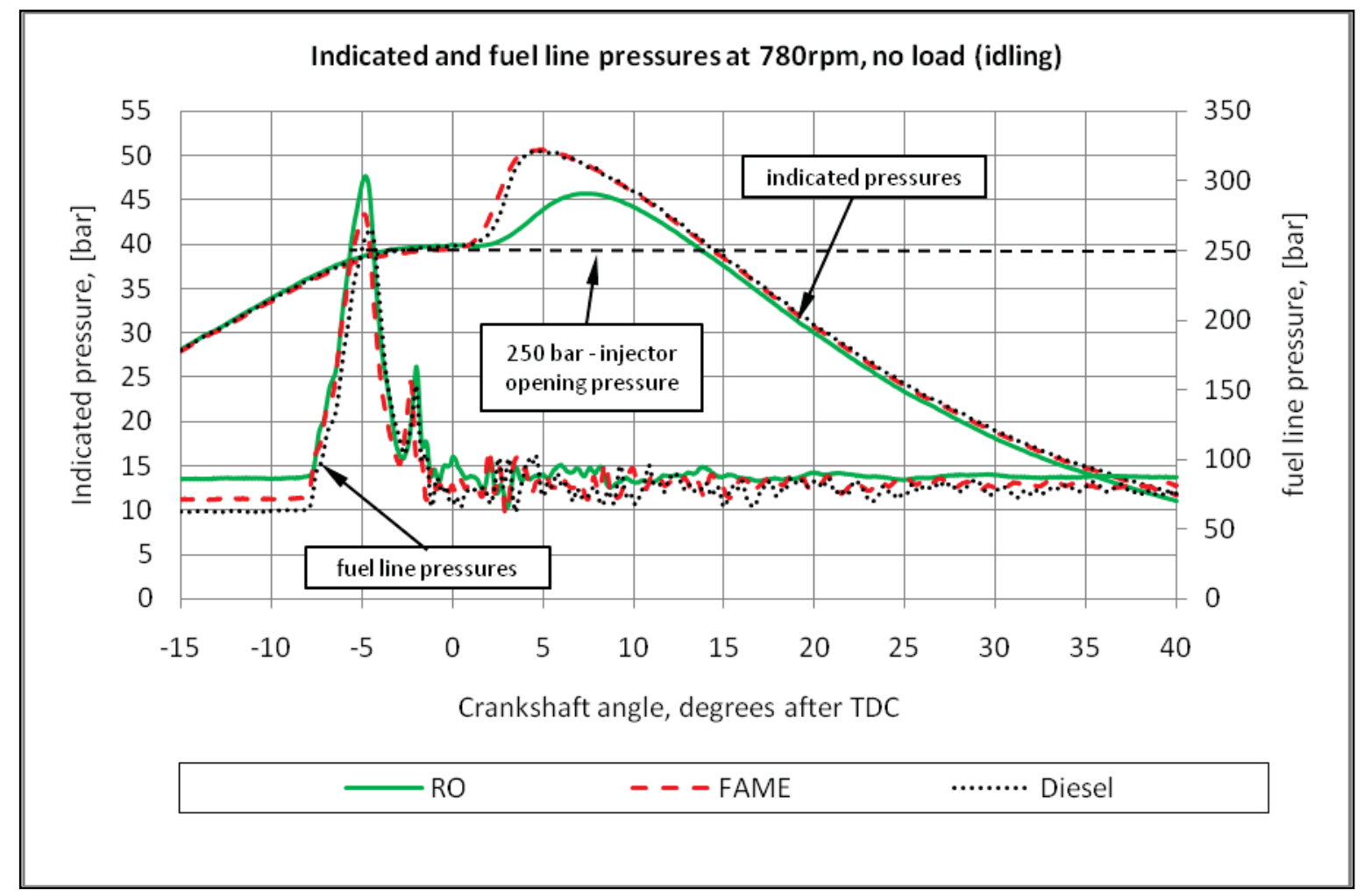

Figure 2g: Indicated and fuel line pressures diagram at $780 \mathrm{rpm}$ and no load (idling)

\section{Discussion}

\subsection{DISCUSSION ON THE START OF INJECTION}

Rapeseed oil has the highest bulk modulus ([5], [7]) of compressibility and the highest velocity of sound (Table 1). Second highest values of these properties are those for methyl ester of rapeseed oil. Because the pressure wave propagation depends on these physical characteristics, having a constant timing of the fuel pump, the injection must start earlier for RO, then for FAME and for diesel.

As could be seen in the figures $2 a$ and $2 b$, there is no difference in the start of injection between researched fuels. The injector-opening pressure is reached in the same position of the crankshaft. The engine is operating in high-speed, high-load regimes and the effects of the different speeds of sound and bulk modules seem to be insignificant here.

With decreasing engine load (Figure 2c), as well as during medium-speed regimes (Figures $2 \mathrm{~d}, 2 \mathrm{e}, 2 \mathrm{f}$ ), the injection of the diesel starts on approximately $0.5^{\circ}$ of the crankshaft later. In these operating modes of the engine, the injector opening position is influenced by the velocity of sound and bulk modulus of the fuels.

A bigger difference was noticed during idling. As it can be seen (Figure $2 \mathrm{~g}$ ), the injector opening pressure of the traditional diesel is reached on $1^{\circ}$ of the crankshaft later. Abovementioned fuel properties have a greater impact in this regime. 


\subsection{DISCUSSION ON THE PEAK FUEL LINE PRESSURE}

Peak fuel line pressure is directly influenced by density and viscosity of the RO, FAME and diesel (Table 1). Higher density and viscosity leads to a higher peak injection pressure. This affirmation was proved during this experiment and can be noticed in all the regimes represented here (Figures $2 \mathrm{a}$ up to $2 \mathrm{~g}$ ). The peak pressure during engine operation on vegetable oil is the highest, followed by the one for methyl ester and diesel.

One thing to be noticed here is that the density and viscosity decrease with increasing temperature. This is the reason why a bigger difference between peak pressure in fuel line for RO and other two fuels can be noticed in low-load regimes (Figures 2c, 2f, 2g). During high-load modes, the peak pressure for rapeseed oil is approaching to the values for the methyl ester and diesel (Figures 2a, 2b, 2d, 2e).

\subsection{DISCUSSION ON THE ONSET OF COMBUSTION, IGNITION DELAY AND PEAK INDICATED PRESSURE}

The peak indicated pressures of all three fuels are approximately the same for all represented regimes, except the medium-speed low-load (Figure 2f) and idling (Figure $2 \mathrm{~g}$ ) regimes, where combustion of rapeseed oil generates lower indicated pressure value in comparison with other two fuels. The difference is much more visible during idling regime (Figure $2 \mathrm{~g}$ ). This phenomenon is a result of the increase of the RO's density and viscosity with decreasing cylinder charge temperature during mixture formation. Increasing fuel's density causes worse fuel atomization and, consequently, poorer combustion.

From the simultaneous measurements of the fuel line and indicated pressures, it can be noticed that at low-load medium speed (Figure $2 \mathrm{f}$ ) and idling (Figure $2 \mathrm{~g}$ ) regimes there is a delayed onset of the combustion and an increased ignition delay for rapeseed oil in comparison with FAME and diesel. As it can be seen from rest of the diagrams, the onset of the combustion delay, as well as ignition delay, diminish with increasing engine load and speed.

During all the engine's operating modes, the usage of methyl ester of rapeseed oil generates indicated pressures very similar to those for traditional diesel, only with some insignificant differences.

Also, ignition delay of the FAME has approximately the same value as the one of the diesel for all the regimes. In low-load regimes (Figures $2 c, 2 f, 2 g$ ), the slightly advance in injection start for the FAME, due to higher density than diesel, is compensated by an advance of a same value in the onset of combustion.

\section{Conclusions}

Physical properties of the rapeseed oil and methyl ester of rapeseed oil have a direct impact on the combustion process and, therefore, on engine output.

FAME has density and viscosity very close to those for conventional diesel. That's why combustion performance of these two fuels is very similar. Several minor differences were noticed during low-load operating modes. Higher density of biodiesel generates higher peak pressure inside the fuel line. Also, it can be noticed a slightly advance in the 
start of injection for methyl ester of vegetable oil. But, due to an advance in onset of combustion of the same value, the ignition delay is equal for both fuels.

Analyzing the results for rapeseed oil, it is clearly distinguished the non-efficient combustion during low-load engine operation. In these regimes, lower indicated pressure is obtained. Higher fuel line pressure doesn't lead to a better atomization. Fuel's increased density, due to decrease of temperature, has a bigger influence and determines a worse atomization. Also, higher values for the ignition delay were obtained in comparison with other two fuels. The onset of combustion takes place later. Higher parameters of the speed of sound and bulk modulus for RO are not able to create an injection advance capable to compensate the combustion onset delay.

The effect of fuels' velocity of sound and bulk modulus is firstly noticed in the high-speed low-load mode and it is increasing with decreasing engine speed.

\section{ACKNOWLEDGEMENTS}

The experimental work was funded by the Czech Science Foundation, project no. 101/08/1717 - "Optimization of the combustion of vegetable oils in diesel engines". The engine was loaned by the Tractor Research Institute (VÚTR) in Brno.

The studies of the Dumitru Bambuleac at Technical University of Moldova are possible with the financial support of the Visegrad Fund (http://visegradfund.org/) scholarship program.

\section{REFERENCES}

[1] Vishal Shah: Emerging Environmental Technologies volume II, USA, Springer, 2010

[2] Vojtíšek M., Barbolla A., Holubec R., Starý P.: Combustion of unesterified plant oils in diesel engines and emissions: Effects of fuel temperature and co-firing with small amounts of hydrogen, ethanol and diesel fuel, Czech Republic, Technical University of Liberec, 2010

[3] Bambuleac D.: Rapeseed oil and methyl ester of rapeseed oil as alternative fuels for diesel engines, Czech Republic, Technical University of Liberec, KOKA 2010, September 06-07 2010

[4] Vojtíšek M., Pechout M., Blazek J., Moc L., Hlavenka T.: Effects of current and prior operating conditions on particulate matter emissions from a diesel engine operated on heated rapeseed oil, SAE 2009-01-1913, 2009

[5] Vojtíšek M., Blazek J., Laurin J., Dufek M., Fenkl M.: Investigation of combustion rates and injection and ignition onset of heated rapeseed oil in direct-injection turbodiesel engines, SAE 2009-01-1914, 2009

[6] Varde K.S.: Bulk modulus of vegetable oil-diesel fuel blends, USA, The University of Michigan-Dearborn, 1983 
[7] Barbolla A.: Rapeseed oil fuel temperature effect in the onset of combustion of diesel engine, Czech Republic, Technical University of Liberec, accepted for presentation at the "Studentská vědecká a odborná činnost na technických fakultách TUL", May 2010

[8] Gregg F.: SVO - Powering your vehicle with straight vegetable oil, New Society Publishers, 2008

[9] Knothe G., Gerpen J.: The biodiesel handbook, AOCS Press, 2005

[10] Gvidonas L., Stasys S.: The effect of rapeseed oil methyl ester on direct injection diesel engine performance and exhaust emissions, Lithuania, Lithuanian University of Agriculture, 2005 